Check for updates

Cite this: RSC Adv., 2018, 8, 17575

\title{
Production of Ti-Fe alloys via molten oxide electrolysis at a liquid iron cathode
}

\author{
Handong Jiao, Donghua Tian, Jiguo Tu (D) and Shuqiang Jiao (D)* \\ This work studies the direct electrochemical preparation of Ti-Fe alloys through molten oxide electrolysis \\ (MOE) at a liquid iron cathode. Cyclic voltammetry and potentiostatic electrolysis have been employed to \\ study the cathodic process of titanium ions. The results show that cathodic behavior happens during the \\ negative sweep at a potential range from -0.80 to $-1.25 \mathrm{~V}$ (vs. QRE-Mo), corresponding to the electro- \\ reduction of titanium ions. Importantly, $\mathrm{Ti}-\mathrm{Fe}$ and titanium-rich $\mathrm{Ti}-\mathrm{Fe}$ alloys have been successfully \\ produced by galvanostatic electrolysis at different current densities of 0.15 and $0.30 \mathrm{~A} \mathrm{~cm}^{-2}$, \\ respectively. The results show that it is feasible to directly prepare $\mathrm{Ti}-\mathrm{Fe}$ alloys by the MOE method at \\ a liquid iron cathode.
}

Received 24th February 2018

Accepted 23rd April 2018

DOI: 10.1039/c8ra01646a

rsc.li/rsc-advances

potentials of metal oxides have been calculated at temperatures ranging from $1473 \mathrm{~K}$ to $1973 \mathrm{~K}$ and the corresponding results are shown in Fig. 1. The calculations indicate that the decomposition potential of $\mathrm{TiO}_{2}$ is far more than that of $\mathrm{FeO}$. Furthermore, the decomposition potential of $\mathrm{Ti}_{2} \mathrm{O}_{3}$ is close to that of $\mathrm{Al}_{2} \mathrm{O}_{3}$. The value of $\mathrm{TiO}$ is even higher than that of $\mathrm{Al}_{2} \mathrm{O}_{3}$, which means that it is difficult to get pure titanium prior to the reduction of $\mathrm{Al}_{2} \mathrm{O}_{3}$ if $\mathrm{TiO}_{2}$ is reduced with a multi-step process. However, the cathodic process of $\mathrm{TiO}_{2}$ could be influenced by the composition of the electrolyte and the cathode metal activity. The published literature has reported that the cathodic process of $\mathrm{Ti}(\mathrm{III})$ ions will change from a two-step reduction $\left(\mathrm{Ti}^{3+}+\mathrm{e}^{-}=\mathrm{Ti}^{2+}\right.$ and $\left.\mathrm{Ti}^{2+}+2 \mathrm{e}^{-}=\mathrm{Ti}\right)$ to a one-step reduction $\left(\mathrm{Ti}^{3+}+3 \mathrm{e}^{-}=\mathrm{Ti}\right)$ with an increase in fluoride ion concentration in molten chloride ${ }^{23,24}$ and the underpotential deposition of $\mathrm{Ti}(\mathrm{III})$ ions will occur at an active cathode, including liquid metal cathodes. $^{25}$

Therefore, this work investigates the feasibility of the direct electrochemical preparation of Ti-Fe alloys by MOE at a liquid iron cathode in a $\mathrm{CaO}-\mathrm{Al}_{2} \mathrm{O}_{3}-\mathrm{MgO}-\mathrm{TiO}_{2}$ melt. Cyclic voltammetry is performed to investigate whether the titanium ions in the oxide melt will be electro-reduced, and galvanostatic electrolysis is carried out to confirm the feasibility of producing TiFe alloys in such oxide melts.

\section{Experimental section}

The selected electrolyte was prepared from $\mathrm{CaCO}_{3}, \mathrm{Al}_{2} \mathrm{O}_{3}, \mathrm{MgO}$ and $\mathrm{TiO}_{2}$ (analytical reagent (AR) grade in purity, Sinopharm Chemical Reagent Co., Ltd.). CaO was obtained by calcination of $\mathrm{CaCO}_{3}$ powder at $1273 \mathrm{~K}$ for $6 \mathrm{~h}$ in a muffle furnace. The mixture with the composition of $47 \mathrm{wt} \% \mathrm{CaO}, 44 \mathrm{wt} \% \mathrm{Al}_{2} \mathrm{O}_{3}$ and $9 \mathrm{wt} \%$ $\mathrm{MgO}$ was initially calcined at $1273 \mathrm{~K}$ for $2 \mathrm{~h}$ to remove moisture. Subsequently, the mixture was placed in a silicon nitride

State Key Laboratory of Advanced Metallurgy, University of Science and Technology Beijing, Beijing, 100083, P. R. China. E-mail: sjiao@ustb.edu.cn; Fax: +86-1062333617; Tel: $+86-10-62333617$ 


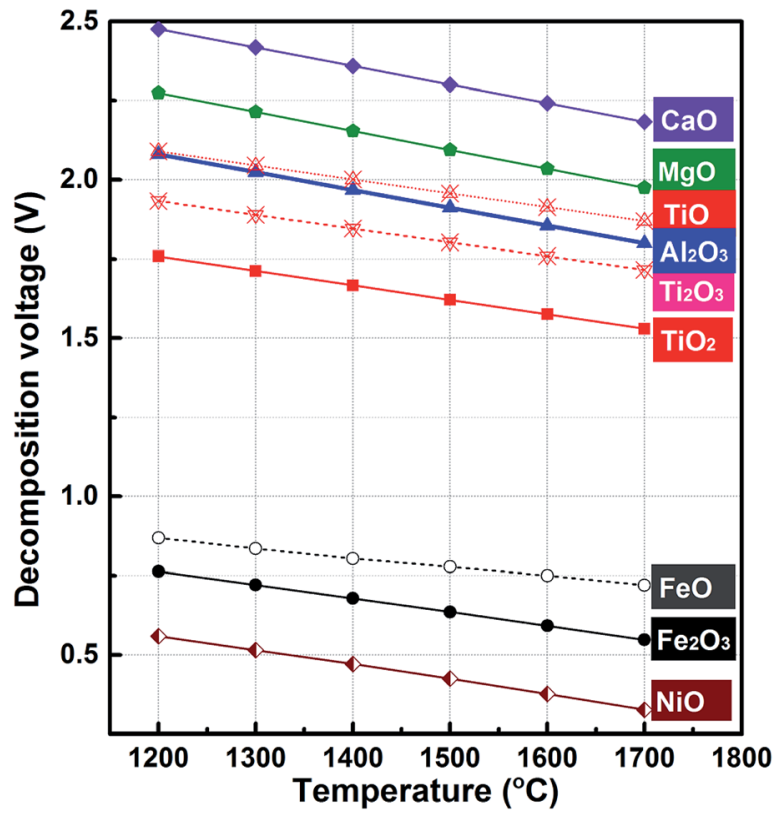

Fig. 1 The decomposition voltages of metal oxides at different temperatures.

crucible (60 $\mathrm{mm}$ in inner diameter, $120 \mathrm{~mm}$ in height) and then heated to melt at $1873 \mathrm{~K}$ in an argon atmosphere. Finally, the pre-melted $\mathrm{CaO}-\mathrm{Al}_{2} \mathrm{O}_{3}-\mathrm{MgO}$ slag was cooled slowly to ambient temperature and then transferred into a glove box. A vertical resistance furnace with the protection of argon at a temperature of $1873 \mathrm{~K}$ was chosen for all experiments.

A three-electrode setup was applied to investigate the electrochemical behavior of titanium ions. The working electrode was molybdenum wire (99.99\%, Alfa Aesar) with a $1 \mathrm{~mm}$ diameter. The pseudo-reference and counter electrodes were molybdenum with a $3 \mathrm{~mm}$ diameter and a $6 \mathrm{~mm}$ diameter, respectively. The potential of the pseudo-reference (QRE-Mo) was satisfactorily stable over a period of 5 hours. Cyclic voltammetry was performed using an electrochemical workstation
(Princeton potentiostat/galvanostat Model 263) connected to a computer with Powersuite software. $5 \mathrm{wt} \% \mathrm{TiO}_{2}$ was directly added into the electrolyte during the testing.

Galvanostatic electrolysis was carried out to further investigate the deposition of titanium at a liquid iron cathode. The powders ( $300 \mathrm{~g}$ in total) were well mixed with the mass fraction $45 \mathrm{wt} \% \mathrm{CaO}, 42 \mathrm{wt} \% \mathrm{Al}_{2} \mathrm{O}_{3}, 8 \mathrm{wt} \% \mathrm{MgO}$ and $5 \mathrm{wt} \% \mathrm{TiO}_{2}$ in the silicon nitride crucible, in which $150 \mathrm{~g}$ high purity iron powder $(\geq 99.99 \%$, particle size: $100 \mu \mathrm{m})$ was placed firstly at the bottom, and then heated to melt at $1873 \mathrm{~K}$. A graphite rod (30 $\mathrm{mm}$ in diameter, $100 \mathrm{~mm}$ in height) was selected as a consumable anode and immersed in the molten slag in this work. Another graphite rod $(3 \mathrm{~mm}$ in diameter, $150 \mathrm{~mm}$ in height) with a silicon nitride insulation layer was immersed in the liquid iron cathode and used as an electrically conducting rod. The vertical distance of the graphite anode from the liquid iron cathode was $10 \mathrm{~mm}$. The galvanostatic electrolysis was operated using a DC power (PSM-3004, GW-INSTEK) at different cathodic current densities of $0.15,0.30$ and $0.45 \mathrm{~A} \mathrm{~cm}^{-2}$.

Characterization of the products was conducted using a scanning electron microscope (JSM6701F) equipped with an EDS probe (Thermo NS7). An X-ray diffractometer (AXIS Ultra, Kratos) was adopted to explore the crystalline structure of the cathodic products. An X-ray photoelectron spectrometer (XPS, Kratos AXIS Ultra DLD) was employed to produce the Ti $2 p$ spectrum.

\section{Results and discussion}

For the cyclic voltammetry measurements, molybdenum wire ( $1 \mathrm{~mm}$ in diameter) was selected as the working electrode. The cyclic voltammogram demonstrated in a blank $\mathrm{CaO}-\mathrm{Al}_{2} \mathrm{O}_{3}-\mathrm{MgO}$ melt at a scan rate of $50 \mathrm{mV} \mathrm{s}^{-1}$ is displayed by the blue dotted line in Fig. 2a. The potential was scanned from the open circuit potential (OCP) at about $0 \mathrm{~V}$ (vs. QRE-Mo) to the negative direction, reversed at $-2.0 \mathrm{~V}$ ( $v s$. QRE-Mo), and returned to the OCP after the position direction scanning at $0.2 \mathrm{~V}$ (vs. QRE-Mo). The results show that there is no obvious redox peak over the
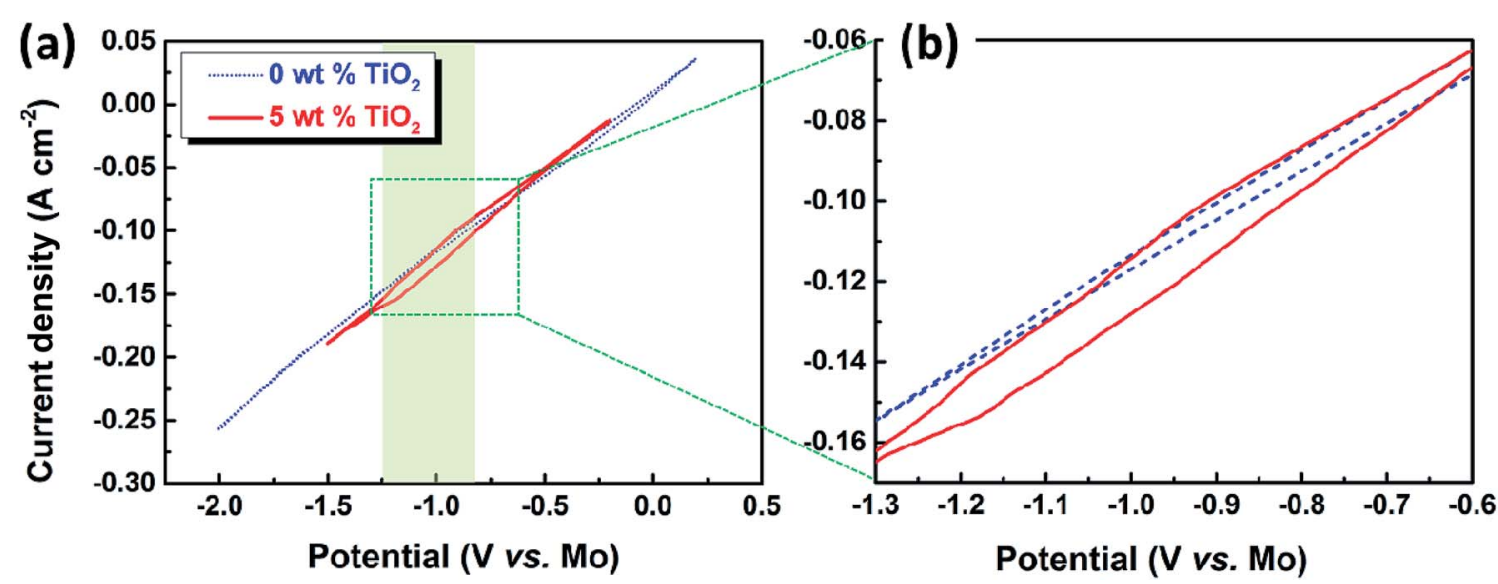

Fig. 2 (a) Cyclic voltammogram of the $\mathrm{CaO}-\mathrm{Al}_{2} \mathrm{O}_{3}-\mathrm{MgO}$ melt before and after dissolving $5 \mathrm{wt} \% \mathrm{TiO}_{2}$, scan rate $50 \mathrm{mV} \mathrm{s}{ }^{-1}$; (b) the partial enlargement of the cyclic voltammogram. 

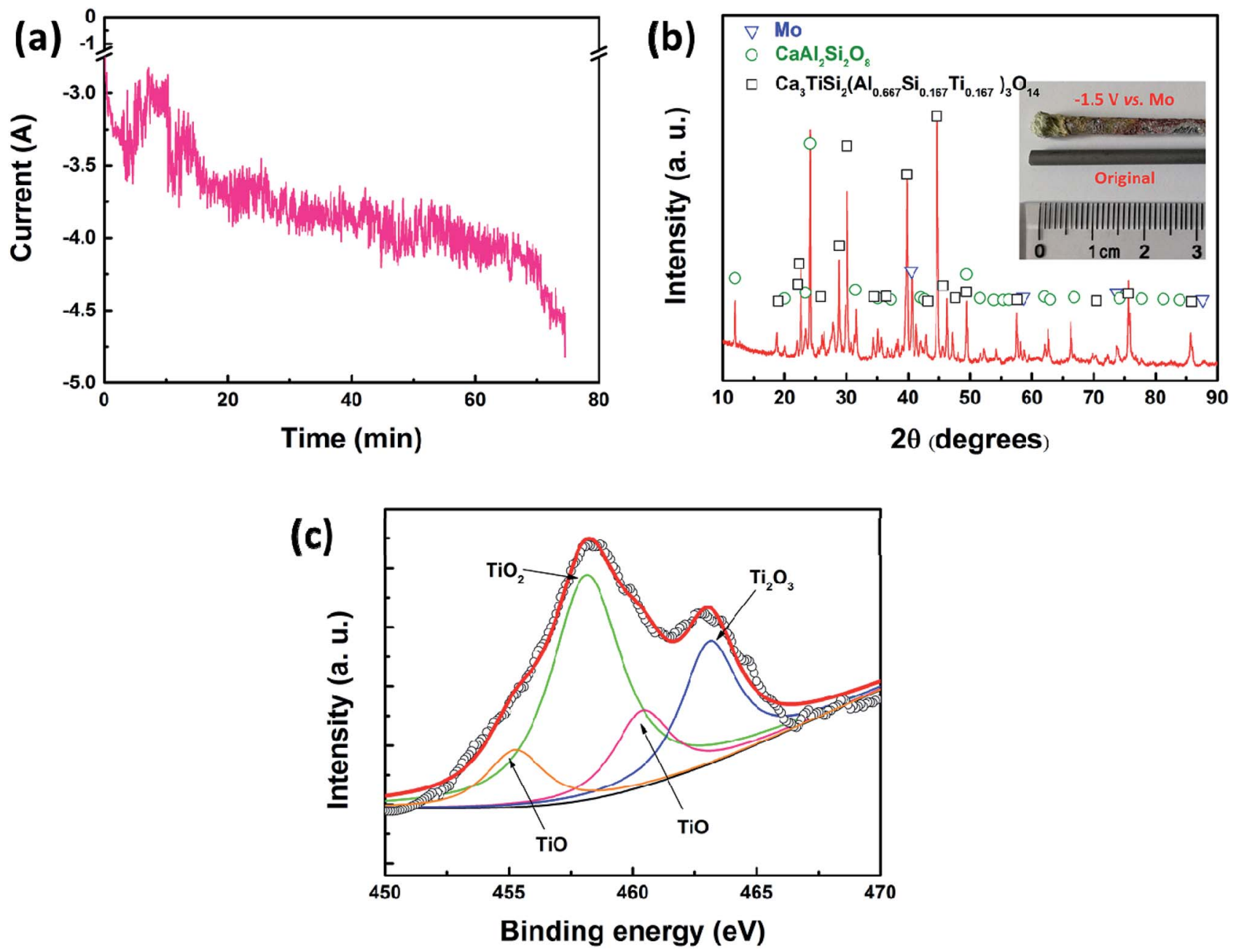

Fig. 3 (a) Current-time curve recorded by potentiostatic electrolysis on a solid molybdenum electrode at a potential of $-1.5 \mathrm{~V} v s$. Mo for 75 min; (b) XRD pattern of the cathodic product (inset is the photograph of the molybdenum electrode); (c) Ti $2 p$ spectrum of the molten oxide electrolyte after electrolysis.

whole scan range. The shape of the voltammogram is similar to a straight line. In contrast, the red solid line representing the cyclic voltammogram of the melt containing $5 \mathrm{wt} \% \mathrm{TiO}_{2}$ shows a reduction wave during the negative sweep at a potential between -0.80 and $-1.25 \mathrm{~V}$ ( $v s$. QRE-Mo), which is shown more clearly in the partial enlargement of the cyclic voltammogram
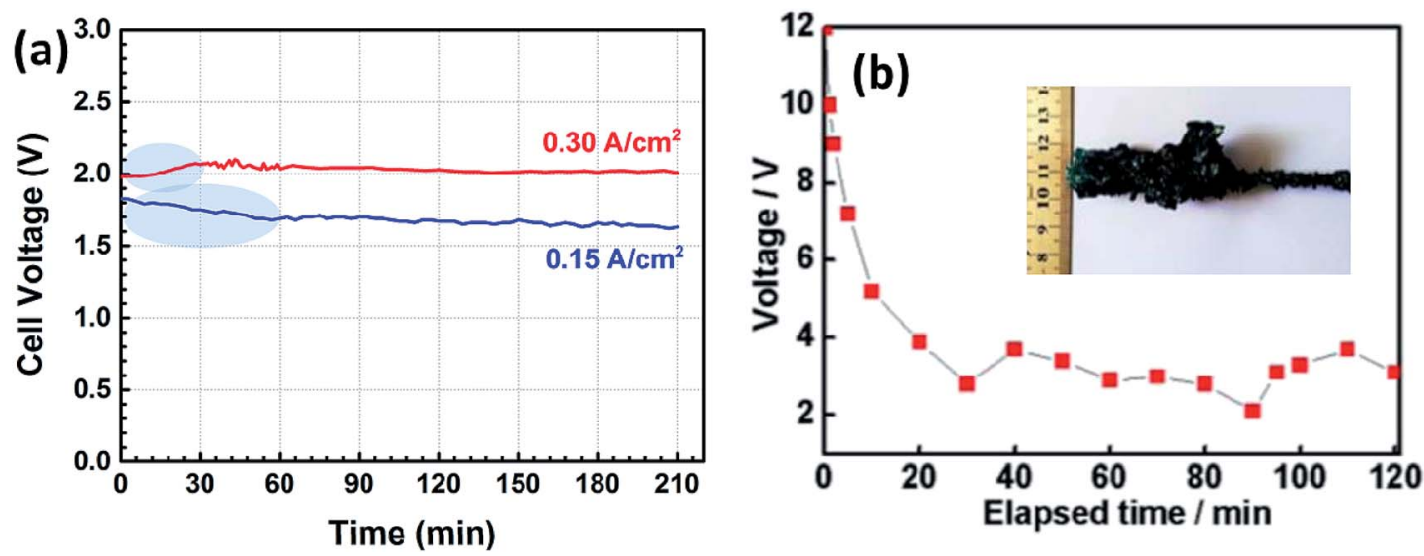

Fig. 4 (a) Cell voltage-time plots recorded by galvanostatic electrolysis at different cathodic current densities of 0.15 and $0.30 \mathrm{~A} \mathrm{~cm}^{-2}$ for $210 \mathrm{~min}$; (b) the cell voltage plot of galvanostatic electrolysis for Fe on a solid molybdenum cathode at a current of $0.85 \mathrm{~A}$ for $2 \mathrm{~h}$ (inset is the photograph of the cathodic product Fe after electrolysis). ${ }^{22}$ 


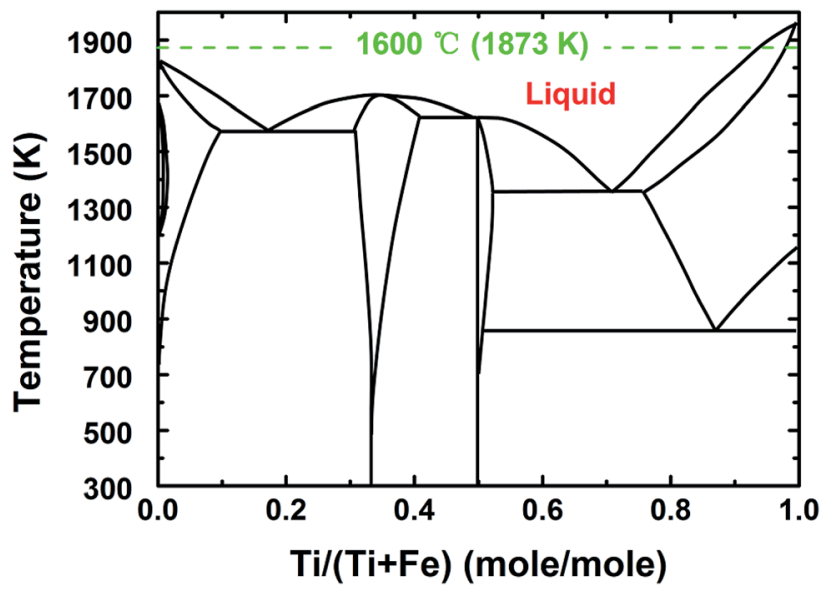

Fig. 5 The phase diagram of $\mathrm{Fe}$ and $\mathrm{Ti}^{23}$

(Fig. 2b). Combining the thermodynamic data shown in Fig. 1 and the previous results of the electrochemical reduction of iron oxide through the MOE method reported by Dihua Wang et al., ${ }^{19}$ in which they showed that the electro-deposition potential of $\mathrm{Fe}(\mathrm{II})$ is about $-0.05 \mathrm{~V}$ (vs. QRE-Mo) at the molybdenum electrode in molten $\mathrm{CaO}-\mathrm{SiO}_{2}-\mathrm{MgO}-\mathrm{FeO}$ slag at $1848 \mathrm{~K}$, the reduction peaks of $\mathrm{TiO}_{2}$ and its suboxides should be around $-0.8-1.25 \mathrm{~V}$ (vs. QRE-Mo), which is in agreement with the results shown in Fig. 2a. These results suggest that $\mathrm{TiO}_{2}$ can be electro-reduced at a solid molybdenum electrode by a multistep process in molten oxide electrolytes.

Subsequently, potentiostatic electrolysis was conducted to further study the reduction process of $\mathrm{TiO}_{2}$ in a molten oxide melt. In this section, molybdenum ( $3 \mathrm{~mm}$ in diameter) was selected as the working electrode and the reference electrode. Graphite (10 $\mathrm{mm}$ in diameter) was used as the counter electrode. The potential was set at $-1.5 \mathrm{~V}$ ( $v s$. QRE-Mo). The current-time curve is shown in Fig. 3a, which indicates that the current increases slowly during electrolysis. Fig. 3b is the XRD pattern of the cathodic product and the inset is the photograph of the molybdenum working electrode. The results show that the cathodic product consists of metal molybdenum and slag. No metal titanium is detected in this product. The Ti $2 \mathrm{p}$ spectrum of the molten oxide electrolyte after electrolysis is studied to further disclose the reduction process of $\mathrm{TiO}_{2}$ at a solid molybdenum electrode and the results are shown in Fig. 3c. It is
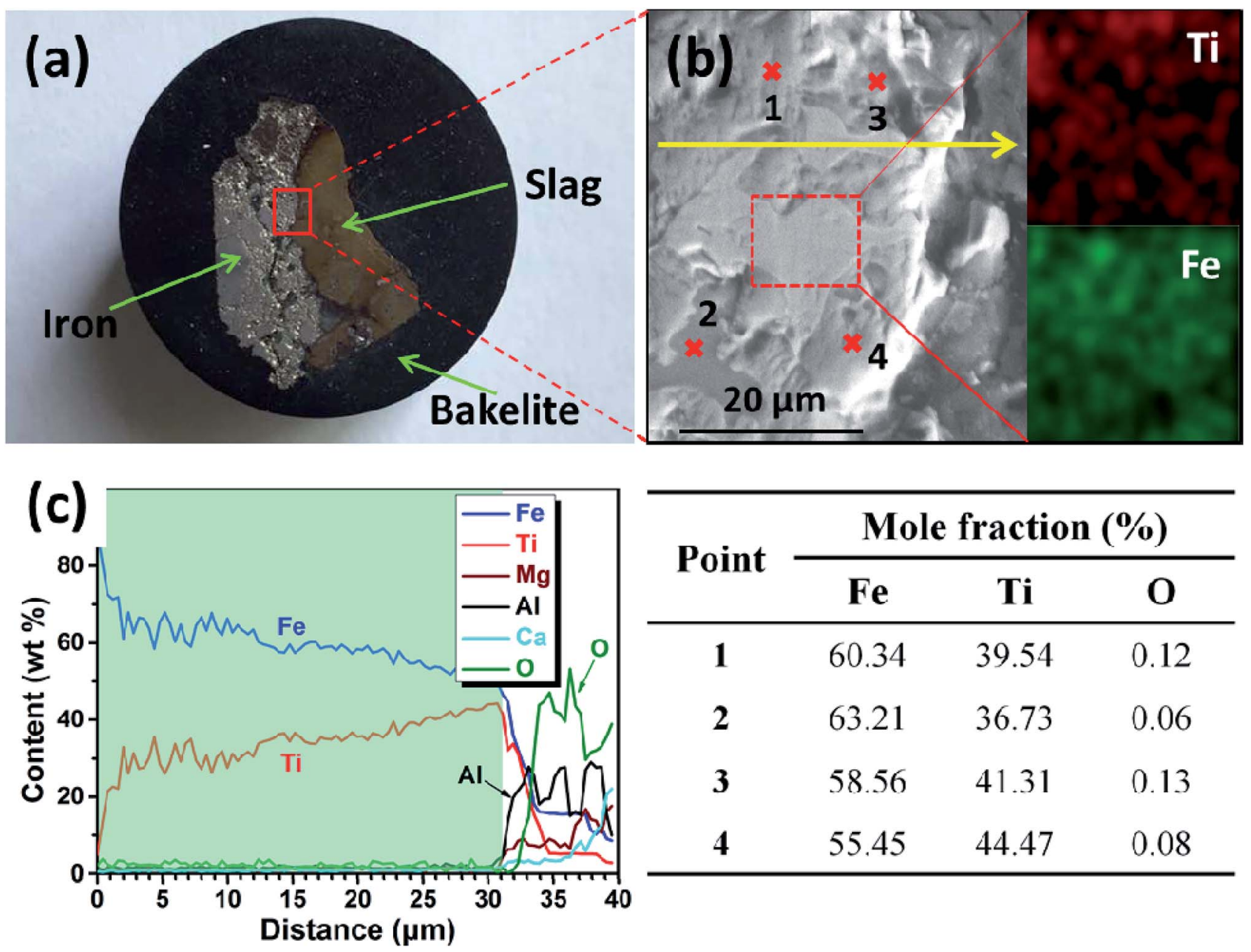

Fig. 6 (a) Photograph of the cross section of the cathodic product obtained by galvanostatic electrolysis at a cathodic current density of $0.15 \mathrm{~A}$ $\mathrm{cm}^{-2}$ for $210 \mathrm{~min}$; (b) SEM image of the cathodic product; (c) EDS line analysis along the solid yellow line shown in (b). 


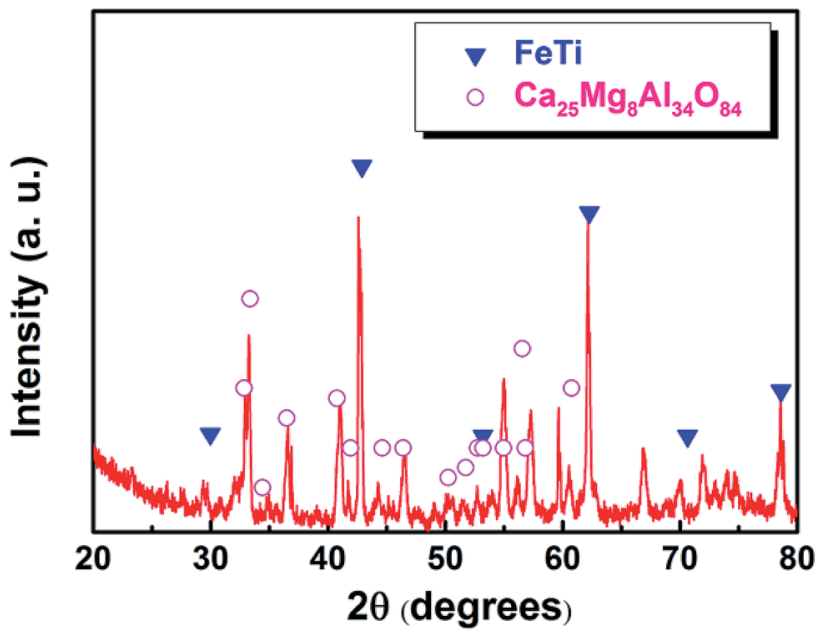

Fig. 7 XRD pattern of the cathodic product obtained by electrolysis at a cathodic current density of $0.15 \mathrm{~A} \mathrm{~cm}^{-2}$ for $210 \mathrm{~min}$.

clearly shown that there are $\mathrm{TiO}$ and $\mathrm{Ti}_{2} \mathrm{O}_{3}$, but no metal titanium. ${ }^{26-29}$ Therefore, the XRD and XPS results indicate that $\mathrm{TiO}_{2}$ can be reduced to $\mathrm{Ti}_{2} \mathrm{O}_{3}$ and $\mathrm{TiO}$, but it may not be further reduced to metal titanium at a solid molybdenum electrode.

To address this issue, a liquid iron cathode was used to obtain the Ti-Fe alloys. For this, galvanostatic electrolysis was conducted on a liquid iron cathode $(60 \mathrm{~mm}$ in diameter $)$ at different cathodic current densities of 0.15 and $0.30 \mathrm{~A} \mathrm{~cm}^{-2}$ for a period of $210 \mathrm{~min}$ on the $\mathrm{CaO}-\mathrm{Al}_{2} \mathrm{O}_{3}-\mathrm{MgO}$ melt containing $5 \mathrm{wt} \% \mathrm{TiO}_{2}$. The cell voltage-time curves during galvanostatic electrolysis were recorded and are shown in Fig. 4a. The voltage obtained at a current density of $0.15 \mathrm{~A} \mathrm{~cm}^{-2}$ has a slight decrease at the initial stage between 0 and $60 \mathrm{~min}$, followed by a steady value of around $1.7 \mathrm{~V}$. In contrast, the voltage obtained at a current density of $0.30 \mathrm{~A} \mathrm{~cm}^{-2}$ has a slight increase between 0 and $30 \mathrm{~min}$, which will be discussed below, and eventually stabilized at $\sim 2.1 \mathrm{~V}$. Both of these are different from the results reported in our previous studies, ${ }^{21,22}$ where we demonstrated the preparation of $\mathrm{Fe}$ and $\mathrm{Fe}-\mathrm{Ni}$ alloys. In those cases, the initial voltage decreases obviously owing to the nucleation of iron at the solid molybdenum electrode and the increase of the surface area of the cathode (as shown in Fig. $4 b^{22}$ ). However, in this work, the cell voltage is relatively stable. This feature is attributed to the good stability of the surface of liquid iron electrode, supported by the phase diagram of Fe-Ti (Fig. $5^{29}$ ), which indicates that there is a large liquid region ranging from 0 to $\sim 93 \mathrm{~mol} \% \mathrm{Ti}$ at $1873 \mathrm{~K}$, preventing the effective formation of dendritic deposits at the iron electrode during electrolysis. Similar behavior is also displayed in our recent work on the recovery of titanium and silicon at a liquid iron cathode from Tibearing blast furnace slag. ${ }^{30}$

After electrolysis at a cathodic current of $0.15 \mathrm{~A} \mathrm{~cm}^{-2}$ for $210 \mathrm{~min}$, the cathodic product was collected by breaking the crucible in a laboratory scale study. Meanwhile, because the separation of metal and slag is difficult at ambient temperatures, the cathodic product covered with a tawny coloured slag is selected to study the deposition of titanium on the surface of the iron cathode. Fig. 6a is a photograph of the cross section of the cathodic product that was inlaid in bakelite. The black area of Fig. 6a is bakelite, the white area with metallic luster is iron or its alloys and the tawny area is slag. This indicates that the interface between iron and slag is relatively smooth compared with the interface between the dendritic deposit and the slag (as shown in Fig. 4b), ${ }^{22}$ This result further verifies that the liquid iron cathode can effectively prevent the formation of dendritic deposits. Fig. 6b shows an SEM image of the cathodic product. According to the EDS map analysis shown in the right of Fig. 6b, titanium and iron are evenly distributed under the selected region of the cathodic product, which preliminarily confirms the feasibility of the preparation of Ti-Fe alloys by MOE at a liquid iron cathode from a $\mathrm{CaO}-\mathrm{Al}_{2} \mathrm{O}_{3}-\mathrm{MgO}-\mathrm{TiO}_{2}$ melt. Subsequently, the possible elements in the cathodic product were analyzed by an EDS line scan, and the results are shown in Fig. 6c, which obviously shows that the impurity elements including aluminum and oxygen are almost negligible in the cathodic product. These results prove that the underpotential deposition of titanium occurs at the liquid iron cathode prior to
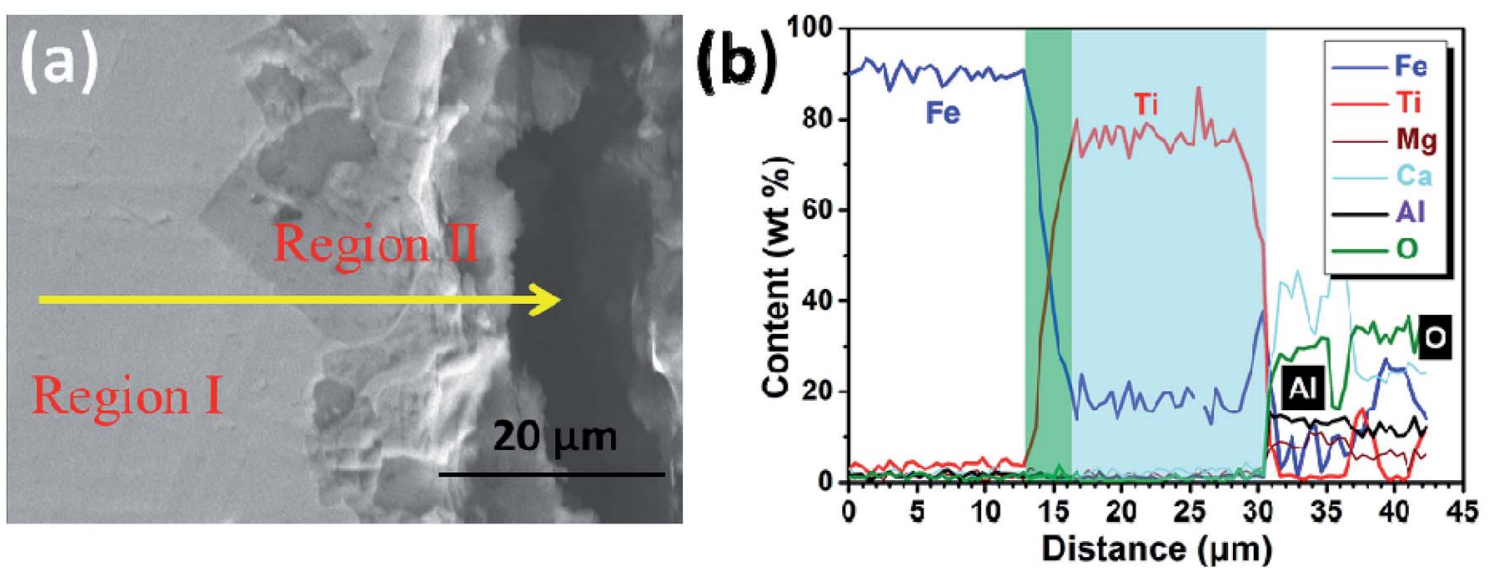

Fig. 8 (a) SEM image of the cathodic product obtained by electrolysis at a cathodic current density of $0.3 \mathrm{~A} \mathrm{~cm}^{-2}$ for $210 \mathrm{~min}$; (b) EDS line analysis along the solid yellow line shown in (a). 

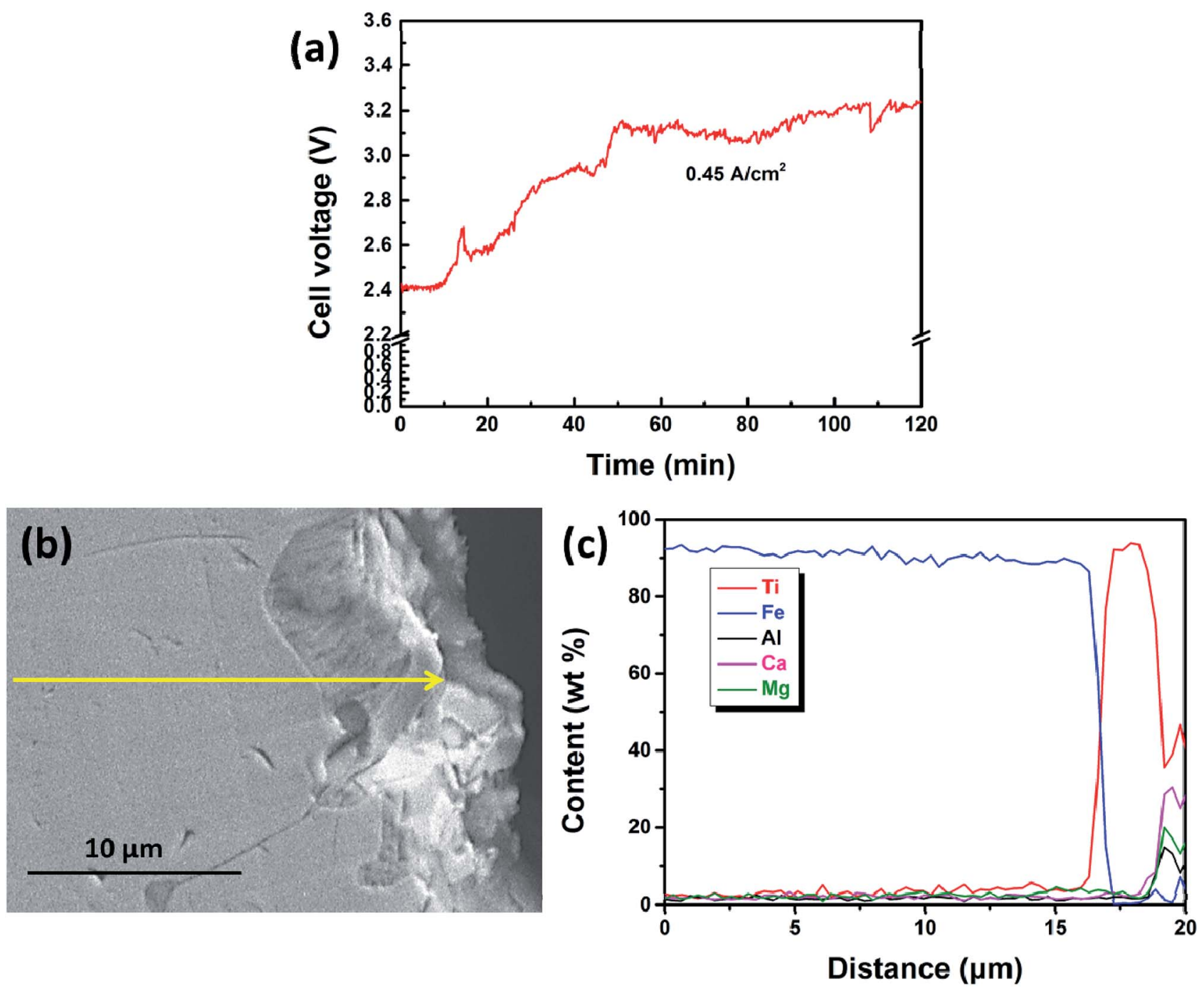

Fig. 9 (a) Cell voltage-time plot recorded by galvanostatic electrolysis at a current density of $0.45 \mathrm{~A} \mathrm{~cm}^{-2}$ for 120 min; (b) SEM image of the cathodic product; (c) EDS line scan along the solid yellow line shown in (b).

the electro-deposition of aluminum. In addition, it is also observed that the titanium content increases gradually with the decrease of distance from the interface between metal and slag, caused by the inter-diffusion process during titanium electrodeposition. The composition at different regions of the product is also disclosed in Fig. $6 \mathrm{~b}$ and the table. They indicate that there is titanium at different regions. In addition, the titanium content of the edge region of the iron cathode (point 3 and 4 ) is more than that of the inner region (point 1 and 2), which is in agreement with the result of the EDS line scan. The XRD pattern of the cathodic product after roughly removing the covered slag is shown in Fig. 7. The presence of Ti-Fe alloys and the slag phase of $\mathrm{Ca}_{25} \mathrm{Mg}_{8} \mathrm{Al}_{34} \mathrm{O}_{84}$ is detected, which is in agreement with the result of the EDS analysis.

Furthermore, the cathodic product obtained by galvanostatic electrolysis at a current density of $0.30 \mathrm{~A} \mathrm{~cm}^{-2}$ for a period of $210 \mathrm{~min}$ is collected in the same way. An SEM image and an EDS line scan of the cross section of the cathodic product are presented in Fig. 8a and b, respectively. It is found that the cathodic product consists of two regions (region I and II) and the interface between these two is pretty obvious. EDS line analysis discloses that the composition of region $\mathrm{I}$ is a lot of iron and little titanium. Region II is composed of titanium and iron, and the titanium content is about three to four times that of the iron content, presenting a titanium-rich Ti-Fe alloy containing low levels of impurities, for example less than $1 \mathrm{wt} \%$ of aluminum and oxygen. In addition, as shown in Fig. 8b, the titanium content increases rapidly at the interface (ranging from 13 to 16 $\mu \mathrm{m})$. This feature may have resulted from the diffusion rate of titanium in pure iron being lower than the electro-deposition rate of titanium at a high current density, and it is similar to the formation of the transition layer between the deposited iron and substrate as shown in previous studies. ${ }^{31}$ This may be the reason why the initial cell voltage increases slightly from $\sim 2.0$ to $\sim 2.1 \mathrm{~V}$ as shown in Fig. 4. The melting point of Ti-Fe alloys decreases with an increase in titanium content and it reaches a minimum when the titanium content is about $70 \mathrm{~mol} \%$ (Fig. 5). At this point, the diffusion rate of titanium in $\mathrm{Ti}-\mathrm{Fe}$ 
alloys is high enough to enable the dissolution of deposited titanium into the cathode, which results in a steady cell potential in the later stage of electrolysis (Fig. 4) and the formation of titanium-rich Ti-Fe with a uniform composition. These findings show that we can prepare Ti-Fe alloys with different titanium contents by changing the electrolysis conditions.

Lastly, the current density was increased to $0.45 \mathrm{~A} \mathrm{~cm}^{-2}$ to study the deposition layer of titanium. The cell voltage shown in Fig. 9a showed a significant increase from $2.4 \mathrm{~V}$ to $3.2 \mathrm{~V}$ in the initial $50 \mathrm{~min}$, unlike that shown in Fig. 4a. SEM and EDS results show that the iron cathode is covered by a thin layer bearing metal titanium. Notably, the thickness (5-6 $\mu$ m thick, as shown in Fig. 9c) of the titanium-bearing layer obtained at 0.45 A $\mathrm{cm}^{-2}$ is much thinner than the thicknesses obtained at current densities of 0.15 and $0.30 \mathrm{~A} \mathrm{~cm}^{-2}$. This further indicates that solid metal titanium or its alloys will appear on the surface of the iron cathode at the initial electrolysis stage because the diffusion rate of titanium in iron is lower than the electrodeposition rate of titanium ions at a high current density. In this case, it is difficult to deposit titanium during electrolysis when the cathode is becoming a solid metal. So, only a thin layer bearing metal titanium is obtained at a high current density of $0.45 \mathrm{~A} \mathrm{~cm}^{-2}$.

\section{Conclusions}

In summary, this work demonstrates the feasibility of producing Ti-Fe alloys with oxide feedstock through the MOE method based on the application of a liquid iron cathode. The finding potentially provides a novel process for alloy preparation from metallurgical slags. Further work will involve detailed fundamental research on this process including the current efficiency, the detailed cathodic process of titanium ions and the optimization of the current density. With the optimization of the electrolysis conditions and anode materials to further lower environmental pollution, we expect that molten oxide electrolysis at a liquid iron cathode can be used to address the predictable resource and cost issues for the preparation of $\mathrm{Ti}-\mathrm{Fe}$ alloys.

\section{Conflicts of interest}

There are no conflicts of interest to declare.

\section{Acknowledgements}

Thanks are given for the financial support from the National Natural Science Foundation of China (No. 51725401 and No. 51474020).

\section{References}

1 J. J. Reilly and R. H. Wiswall Jr, Inorg. Chem., 1974, 13, 218222.

2 N. Endo, S. Suzuki, K. Goshome and T. Maeda, Int. J. Hydrogen Energy, 2016, 42, 5246-5251.
3 M. W. Davids and M. Lototskyy, Int. J. Hydrogen Energy, 2012, 37, 18155-18162.

4 N. Endo, I. Saita, Y. Nakamura, H. Saitoh and A. Machida, Int. J. Hydrogen Energy, 2015, 40, 3283-3287.

5 X. Wang, F. Han, X. Liu, S. Qu and Z. Zou, Wear, 2008, 265, 583-589.

6 D. Liu, R. Liu and Y. Wei, Surf. Coat. Technol., 2012, 207, 579586.

7 M. Pourabdoli, S. Raygan, H. Abdizadeh and K. Hanaei, Can. Metall. Q., 2007, 46, 17-23.

8 L. Zaluski, P. Tessier, D. H. Ryan, C. B. Doner, A. Zaluska and J. O. Strömolsen, J. Mater. Res., 1993, 8, 3059-3068.

9 H. Hotta, M. Abe, T. Kuji and H. Uchida, J. Alloys Compd., 2007, 439, 221-226.

10 T. Saito, J. Alloys Compd., 2004, 364, 113-116.

11 W. J. Kroll, Trans. Am. Electrochem. Soc., 1940, 78, 35-47.

12 G. Z. Chen, D. J. Fray and T. W. Farthing, Nature, 2000, 407, 361-364.

13 M. Panigrahi, E. Shibata, A. Iizuka and T. Nakamura, Electrochim. Acta, 2013, 93, 143-151.

14 M. Ma, D. Wang, X. Hu, X. Jin and G. Z. Chen, Chem.-Eur. J., 2006, 12, 5075-5081.

15 X. S. Ye, X. G. Lu, C. H. Li, W. Z. Ding, X. L. Zou, Y. H. Gao and Q. D. Zhong, Int. J. Hydrogen Energy, 2011, 36, 45734579.

16 D. R. Sadoway, J. Mater. Res., 1995, 10, 487-492.

17 H. Kim, J. Paramore, A. Allanore and D. R. Sadoway, J. Electrochem. Soc., 2011, 158, E101-E105.

18 A. Allanore, L. Yin and D. R. Sadoway, Nature, 2013, 497, 353356.

19 D. Wang, A. J. Gmitter and D. R. Sadoway, J. Electrochem. Soc., 2011, 158, E51-E54.

20 A. H. Sirk, D. R. Sadoway and L. Sibille, ECS Trans., 2010, 28, 367-373.

21 K. Zhang, H. Jiao, Z. Zhou, S. Jiao and H. Zhu, J. Electrochem. Soc., 2016, 163, D710-D714.

22 Z. Zhou, H. Jiao, J. Tu, J. Zhu and S. Jiao, J. Electrochem. Soc., 2017, 164, E113-E116.

23 F. Lantelme and A. Salmi, J. Electrochem. Soc., 1995, 142, 3451-3456.

24 J. Song, Q. Wang, J. Wu, S. Jiao and H. Zhu, Faraday Discuss., 2016, 190, 421-432.

25 H. Jiao, J. Wang, L. Zhang, K. Zhang and S. Jiao, RSC Adv., 2015, 5, 62235-62240.

26 H. Reimers, J. Gold, B. Kasemo and D. Chakarov, Appl. Phys. A, 2003, 77, 491-498.

27 H. F. Franzen, M. X. Umaña, J. R. Mccreary and R. J. Thorn, J. Solid State Chem., 1976, 18, 363-368.

28 D. Gonbeau, C. Guimon, G. Pfister-Guillouzo, A. Levasseur, G. Meunier and R. Dormoy, Surf. Sci., 1991, 254, 81-89.

29 C. W. Bale, E. Bélisle, P. Chartrand, S. A. Decterov, G. Eriksson, A. E. Gheribi and A. D. Pelton, Calphad, 2016, 54, 35-53.

30 H. Jiao, D. Tian, S. Wang, J. Zhu and S. Jiao, J. Electrochem. Soc., 2017, 164, D511-D516.

31 J. H. Liu, G. H. Zhang and K. C. Chou, J. Electrochem. Soc., 2015, 162, E314-E318. 